\title{
A Dual-Step and Dual-Process Model of Advertising Effects: Implications for Reducing the Negative Impact of Advertising on Children's Consumption Behaviour
}

\author{
Oliver B. Büttner
}

Arnd Florack

Benjamin G. Serfas

University of Vienna, Austria

\section{Author Note}

This research was supported by a Marie Curie FP7 Integration Grant within the 7th European Union Framework Programme to Oliver B. Büttner (FP7-PEOPLE-2011-CIG 293577).

Correspondence should be addressed to Oliver B. Büttner, Applied Social Psychology and Consumer Research; University of Vienna, Universitätsstraße 7, 1010 Vienna, Austria. E-mail: oliver.buettner@univie.ac.at

Cite as: Büttner, O. B., Florack, A., \& Serfas, B. G. (2014). A dual-step and dual-process model of advertising effects: Implications for reducing the negative impact of advertising on children's consumption behaviour. Journal of Consumer Policy, 37(2), 161-182. 


\title{
A Dual-Step and Dual-Process Model of Advertising Effects: Implications for Reducing the Negative Impact of Advertising on Children's Consumption Behaviour
}

\begin{abstract}
Children are important targets of advertising campaigns from companies. However, children have been found to be particularly vulnerable to negative effects of advertising, and protecting children from these effects is an important task of consumer policy. Two important aspects have to be considered in this task. First, advertising affects judgments and behaviour not only during ad exposure, but also in delayed consumption and purchase contexts. Second, advertising thrives largely at an implicit level - during ad exposure as well as in consumption decisions. The current article introduces a dual-step (ad exposure vs. purchase/consumption) and dual-process (implicit vs. explicit) model of advertising effects on children. The model is based on a review of implicit advertising effects and implicit mechanisms of self-control. It implies that consumer policies intending to prevent undesired advertising effects should support interventions with the goal of strengthening advertising and purchasing literacy and, in addition, implicit self-control mechanisms in children. As self-control in consumption decisions is largely relevant for, and learned during, shopping and consumption, such interventions should focus on educating parents or other primary caregivers, because they are the most likely persons to accompany children in such situations and have a great influence on children's implicit learning.
\end{abstract}

Keywords Consumer Behaviour ' Children · Advertising 'Self-Control · Dual-Process Models 


\section{A Dual-Step and Dual-Process Model of Advertising Effects: Implications for Reducing the Negative Impact of Advertising on Children's Consumption Behaviour}

\section{Introduction}

A great percentage of advertisements aired during children's TV programmes directly promote products created for use or consumption by children, such as toys, video games, or food (Desrochers and Holt 2007; Gantz et al. 2007). Furthermore, online advertisements, advertisements in computer games, and product placements within films or soap operas are often directed towards children (Hang and Auty 2011; Karrh 1998; Yang et al. 2006). Even sponsoring and advertising in preschools and schools is becoming more and more common (Calvert 2008). Hence, it is not surprising that the advertising budgets of companies that make products for use or consumption by children are high (Piachaud 2008). For example, according to recent estimates, the costs for advertising for toys alone were about 100 million EUR in 2008 in Germany (Thomson Media Control 2009).

Children are an attractive target group. They have direct access to financial resources, such as pocket money. More importantly, they strongly influence the purchase decisions of parents and other relatives (Buijzen and Valkenburg 2008). The high degree of media contact that children have facilitates the advertising activities that are directed towards this target group (Dennison et al. 2004). Even though the concrete estimates differ between countries, there is no doubt that children spend a lot of their time watching TV or conducting activities online. Recent data from a survey in Germany, for instance, illustrates that, on average, children between 3 and 5 years old watch TV more than eight hours a week (Feierabend and Klingler 2012). Another source reports for the same country that $50 \%$ of children between 6 and 16 years are online at least once a day (Elements of Art GmbH et al. 2010).

Advertising to children, however, has evoked public concern. There is a widespread opinion that children are particularly vulnerable to the effects of advertising, and that regulations are needed to protect them (for an overview, see Calvert 2008; Kunkel et al. 2004). In particular, the increasing rate of obesity among children has drawn attention to the negative effects of advertising on children's food attitudes and choices (Livingstone and Helsper 2006). However, advertising effects may even extend beyond just influencing desire for the advertised products. Previous research suggests that exposure to advertising fosters the development of materialistic attitudes, and evokes conflicts between children and parents (Buijzen and Valkenburg 2003; Galst and White 1976; Goldberg and Gorn 1978). Moreover, 
researchers have examined whether unrealistic images - such as ultra-thin models - affect the formation of ideal self-images (Anschutz et al. 2011), which might harm self-esteem and lead to eating disorders (Anschutz et al. 2012). While these lines of research focus on children's vulnerability to advertising, there are also approaches that highlight children's competencies and skills to resist persuasion (Buckingham 2007, 2009; Kline 2010).

Recurring questions for consumer policy include how to reduce negative effects of advertising on children, and how to strengthen children's competencies as young consumers (e.g., Kline 2010; Graff et al. 2012). For this purpose, it is important to obtain insights into the processes that determine how advertising affects children's perceptions, judgements, and behaviour. Only if there is knowledge about the processes underlying advertising effects on children can adequate tools to prevent children from these effects and to strengthen their consumption competence be applied successfully. In the present article, we present a dualstep and dual-process model of advertising effects on children. The dual-step perspective addresses the fact that advertising influences judgments and behaviour not only during ad exposure, but also in delayed consumption and purchase contexts. The dual-process perspective takes into account that the success of advertising is shaped by implicit and explicit processes. Implicit processes refer to unconscious and automatic effects of advertising. Explicit processes refer to advertising effects that can be recognized and monitored consciously.

Our dual-step and dual-process perspective on advertising and children provides three major contributions. First, our perspective extends the view of advertising effects on children from the moment of ad exposure to the moment a consumption decision is made. Second, it extends the current view of advertising effects on children from a focus on explicit ways of understanding and resisting advertising to a perspective that acknowledges the role of implicit processes both during ad processing and in consumption decisions. Third, our perspective provides opportunities for additional interventions to protect children from negative effects of advertising.

To elucidate the proposed model, we start with a review of the literature on media literacy and persuasion knowledge. Next, we discuss recent developments that address implicit processes and children's limited cognitive control. Then, we introduce our dual-step (creating memory structures vs. influence of memory structures in purchase and consumption contexts) and dual-process (implicit vs. explicit) model of advertising. Finally, we discuss interventions that take into account that advertising works largely via implicit processes. 


\section{Resistance to Persuasion}

\section{Persuasion Knowledge and Media Literacy}

Children's media literacy and persuasion knowledge is often regarded as key for preventing undesired advertising effects (Brown 2001; Wright et al. 2005). Several researchers argue that a number of skills are needed to successfully control advertising effects, and that children do not possess all of these skills (e.g., Austin and Johnson 1997; Brucks et al. 1988; Roberts 1983). For example, these researchers put forth the idea that children should be able to detect an advertisement and distinguish its content from the normal TV programme to control advertising effects. Further, they illustrate that children should be aware that advertisers have a different perspective to them, and identify the persuasive intent. Finally, they point out that children need to be aware that advertising does not always mirror reality, and that advertisers may use bias and deception in advertising.

In the same vein, other researchers argue that a certain level of cognitive development is necessary to resist advertising in the moment of exposure (Kunkel et al. 2004). The stage model of consumer socialization posited by John (1999) suggests that children between 3 and 7 years of age process advertising on a perceptual level from an egocentric viewpoint, and do not take the perspectives of others into account. Similarly, other authors (e.g., Moses and Baldwin 2005) refer to the theory of mind and argue that until the age of 6 children do not develop an understanding of the beliefs and motives of other individuals, which is regarded as a prerequisite for an understanding of persuasion (Friestad and Wright 1994). Based on this argument, a task force of the American Psychological Association on advertising and children recommended restrictions on advertising targeted at children below the age of 8 (Kunkel et al. 2004).

Some authors argue that training is required to improve children's ability to identify the persuasive intent of advertising, and to reduce advertising effects. Austin and Johnson (1997) applied media literacy training, during which children saw a video that described techniques developed by advertisers to present products in a very positive way. The training included a discussion of several advertising practices mentioned in the video. In a post-test, which followed the training, the children who took part in the training were more likely to understand the intention of the ads presented to them, compared to children who did not participate. In a delayed post-test conducted three months after the training, these children were still more realistic about whether people in ads behave like real people do. In a similar 
study, Roberts et al. (1980) found that children were more sceptical about advertising after watching a video describing advertising techniques.

To sum up, these lines of research suggest that certain cognitive competences have to be developed to control advertising effects, and that media literacy might help to reduce the immediate effects of advertising during or shortly after exposure. However, recent research that focuses on the implicit effects of advertising and children's limited capacity for information processing and self-control (e.g., Livingstone and Helsper 2006; Buijzen et al. 2010) challenges this conclusion.

Recent Models: Implicit Effects of Advertising and Cognitive Control

Recently, a number of reviews and theoretical articles have discussed the implicit effects of advertising. Livingstone and Helsper (2006), for example, refer to the unexpectedly weak correlation between age and advertising effectiveness, and argue that advertising can influence behaviour not only at an explicit level, but also on an implicit one. They further point out that effects assigned to the implicit level are not mitigated by advertising literacy. Similarly, Nairn and Fine (2008) put forward that common advertising formats for children are more likely to affect behaviour via implicit processes. Finally, the framework for young people's Processing of Commercialized Media Content (PCMC; Buijzen et al. 2010) integrates dual-process models of message elaboration and unconscious processing. The PCMC model includes three levels of message elaboration: systematic processing, heuristic processing, and automatic processing. Buijzen et al. (2010) argue that children are more prone to process advertising at lower levels of elaboration because of their developmental immaturity.

Other authors have stressed the role of cognitive control, which includes functions, such as response inhibition, that are necessary to override automatic reactions (Garon et al. 2008). In addition to persuasion knowledge, resistance to persuasion requires the ability to activate this knowledge and to act on it (Moses and Baldwin 2005). Moses and Baldwin (2005) argue that the prefrontal cortex - a brain structure that guides cognitive control - does not become fully developed until early adulthood (Welsh et al. 1991). The Food Marketing Defense Model (FMDM; Harris et al. 2009b) similarly posits that persuasion knowledge alone is not sufficient, due to the presence of several implicit influences and processes during ad exposure to children. According to the FMDM, four factors are essential to resist persuasion: awareness, understanding, ability, and motivation. Likewise, Rozendaal et al. (2011) refer to cognitive control when they argue that applying advertising literacy requires a 
"stop-and-think-response", which means that children shift their attention from the advertising to thinking about its persuasive intent, and to applying counter strategies. According to the authors, developmental changes in cognitive functioning and emotion regulation make it unlikely that children engage in such stop-and-think responses. Moreover, the authors stress that the majority of commercials targeted at children are designed to affect attitudes through low-effort processing, which will not trigger a stop-and-think response. Thus, even if children have a conceptual knowledge about advertising, whether they can use and apply this knowledge is questionable.

In sum, the findings on implicit advertising effects and cognitive control imply that persuasion knowledge and media literacy only have limited success in protecting children from advertising. The reason for this is that applying these competencies requires processing and cognitive resources that will either (a) not be triggered because of low-level, implicit persuasion processes, or (b) not be fully available because of pending developmental processes in children.

\section{Shortcomings of Existing Models}

Even though recent approaches on advertising effects on children include assumptions on the implicit effects of advertising, they share an important shortcoming with the persuasion knowledge and media literacy approach: They focus mainly on the reception situation, and thereby neglect three important aspects.

First, advertising often affects behaviour in a context where the advertisement is not present. Ad-based memory structures and attitudes mainly influence consumer decisions in contexts (e.g., in the supermarket) that are different from the context of exposure to the advertisement (e.g., when watching TV). This implies that there are at least two opportunities in which young consumers can succeed or fail in guarding themselves against advertising effects: at the time of advertising exposure, and at the time of decision making and consumption. Moses and Baldwin (2005) comment that even when children make the right conclusions about an advertisement, they may "on entering the marketplace ... nonetheless purchase the product against their better judgment" (p. 195). Thus, it is not surprising that the evidence for a link between exposure to advertising and actual consumption behaviour is mixed (Hastings et al. 2003; Livingstone and Helsper 2006). Based on such a reasoning, Young (2010) questions the external validity of studies in which children are asked to choose a product directly after being confronted with material that includes an advertisement for one of the products. 
Second, the interplay between implicit and explicit processes has to be taken into account - both for advertising reception and for consumption decisions (Strack et al. 2006). Buijzen et al. (2010) posit that attitudes that are based on implicit processing result in impulsive consumer decisions, whereas attitudes that are based on explicit processing result in deliberate consumer decisions. Research on consumer decisions, however, shows that whether implicit and explicit processes influence choice depends strongly on the context in which the choice is made, and not only on how the attitudes were formed (Florack et al. 2010; Scarabis et al. 2006).

Third, existing models focus mainly on explicit processes as a way to resist persuasion, and claim that resisting persuasion requires the ability and motivation to process information and to show self-control (Harris et al. 2009b; Moses and Baldwin 2005). An exception to this is highlighted in work by Rozendaal et al. (2010), who mention highly automatized (negative) attitudes toward advertising as a possible implicit defence against advertising. This is a promising idea, but, again, it is intended to work during the processing of an advertisement and not during decision-making. In our model, we elaborate on the aspect that implicit defences can counteract implicit influences, and thus bolster self-control. We focus on selfcontrol during consumption, and not during ad processing.

\section{A Dual-Step and Dual-Process Model of Advertising Effectiveness}

The model presented in this manuscript has two major objectives. The first is to extend the view of advertising effects on children from the moment of ad processing to the moment a consumption decision is made. The second objective of our model is to extend the view of advertising effects on children from a perspective that is mainly concerned with the reflective understanding of advertising and explicit ways of resting advertising to a perspective that stresses the implicit processes that underlie advertising effects and the implicit ways in which children's self-control can be strengthened.

According to the model (Figure 1), advertising influences behaviour in two steps: First, advertising creates memory structures (e.g., attitude, brand knowledge). Second, these advertising-based memory structures influence consumption decisions at a later point in time. Both implicit and explicit processes are important at both steps. Children build advertisingbased memory structures via explicit and implicit learning. Consumption decisions are influenced by impulses from the implicit system, and by deliberation via the explicit system. 


\section{XXXXX INSERT FIGURE 1 XXXXX}

\section{The Two Steps of Advertising Effectiveness}

The advertising effects that are most interesting for marketers are based on learning (Grunert 1994). The final goal of advertising is to influence consumers' purchase decisions in favour of the advertised brand. However, the moment during which a consumer is confronted with an advertisement is usually not the same as the moment when the consumer makes a related consumption decision (Baker and Lutz 1988, 2000). Thus, a central goal of advertising is that consumers learn something about a brand, which increases the likelihood that consumers will consider the brand as a purchase option. The outcome of this learning through advertising is reflected in consumers' memory structures, such as brand knowledge and attitude toward the brand. If children, for instance, watch a TV ad featuring a brand of breakfast cereals, they may learn that these cereals can be eaten for breakfast and that they are tasty, which may result in a positive attitude towards the brand.

Past research (e.g., Bijmolt et al. 1998; Brucks et al. 1988), as well as recent models (Buijzen et al. 2010; Harris et al. 2009b), has concentrated on advertising effects at the moment the consumer is confronted with commercials. But the influence of advertising on consumption also involves a second step in order to be effective. Children's purchase decisions, or their influence on parents' purchase decisions, are likely to occur in a moment when the advertising-based memory structures are activated. Both internal and external triggers can activate these memory structures. An example of an internal trigger is hunger; an example of an external trigger is seeing a soft drink in the supermarket.

Thus, the chain between advertising and children's consumption behaviour may be influenced at two points. First, interventions may target the moment when children see an advertisement to increase scepticism towards the advertisement (e.g., Rozendaal et al. 2010). The goal of such interventions is that children form a cognitive representation that is not only shaped by the mere reception and understanding of the advertisement, but also by a critical assessment of the advertisement's goals. This is also addressed by the persuasion knowledge and media literacy approach (see also Wright et al. 2005).

Second, interventions aimed at protecting children from the negative effects of advertising on consumption may target situations in which advertising-based memory structures influence children's consumption behaviour. Previous research has remained silent on this aspect. However, considering this as 'Step 2' in our model is important, because advertising effects are often unconscious (e.g., Gibson 2008; Fang et al. 2007) and consumers 
often do not recall the source of persuasive messages while being still influenced by the message itself (Florack et al. 2002; Gillig and Greenwald 1974; Hovland and Weiss 1951; Kumkale and Albarracin 2004; Pratkanis et al. 1988). Furthermore, even having knowledge of the influence of an advertisement can fail to reduce its effect when individuals do not activate the related self-control goals, or when they lack the necessary self-control resources or abilities (Muraven and Baumeister 2000).

Development and Differences between Explicit and Implicit Processing

Our reasoning that dual processes underlie advertising effects is based on the now widely acknowledged conception that there are multiple levels at which individuals process information. A number of dual-process models from cognitive and social psychology (Fazio 1986; Frank et al. 2009; Grunert 1994; Kahneman 2003; Shiffrin and Schneider 1977; see Evans 2008 for an overview) distinguish between two different information-processing systems: an explicit system that entails a controlled, explicit way of information processing, and an implicit system involving an automatic, implicit way of information processing. In the explicit system, information processing is conscious and occurs in a sequential way. It is based on rules and reasoning. It can learn information from single experiences, and is the source of cognitive control and volition. The drawback of the explicit system is that its capacity is limited. Explicit thinking is limited to one thought at a time, and cognitive control needs resources. In the implicit system, learning occurs in an associative, probabilistic way, and needs many experiences. Thus, the implicit system learns slowly. However, the system is based on unconscious parallel processing, with a huge capacity to process many pieces of information at a time. A basic difference between explicit and implicit processing is that explicit processing involves higher-order structures located in the prefrontal cortex of the brain, compared to implicit processing (Casey et al., 2005). Another difference is that explicit and implicit processing are at least partly based on different memory systems. Implicit processing is based on an associative memory system that is linked to the activation of neurons in the basal ganglia, and explicit processing relies on a memory system that is based on episodic memory involving neurons from the hippocampus (Frank et al. 2006).

To illustrate the two systems, imagine a child being given a choice between two brands of chocolate. The explicit system might provide the child with the information that he or she has consumed the chocolate before, or that he or she has seen an ad about the chocolate. In contrast, the implicit system provides behavioural impulses, but does not allow insights into the bases of the impulses. Imagine that the child was exposed to some ads for one of the 
chocolate brands, and the implicit system formed associations of this brand with eating and taste. Later, the child might not be aware of the prior exposures, but follows the automatic impulse towards the brand, which has its origin in the prior exposure.

From an evolutionary perspective, the explicit system is regarded as more recent and unique to humans, whereas the implicit system is evolutionarily older and shared with other animals (Barrouillet 2011; Reber 1989). This developmental path is also assumed to exist at the ontogenetic level, and to cause differences in implicit and explicit processes at different ages: The explicit system is supposed to mature and develop throughout childhood, whereas the implicit system is assumed to function from early childhood on (Barrouillet 2011; Reber 1989). A basic reason for the differences in the development of explicit and implicit processing is the continuing development of the brain after birth. Though at the age of five years children have a fully developed brain in terms of volume and general structure (Giedd et al. 1996), grey and white matter continues to be redefined (Nagy et al. 2004). Regions that are associated with cognitive control (e.g., working memory and performance in cognitive tasks), which is a key part of explicit processing, develop relatively late (Sowell et al. 2004). Furthermore, it is not only the development of the brain structure that is of importance for explicit processing, but also the developing connectivity between the different areas of the brain (Edin et al. 2007). The abovementioned differences in the functioning of the brain explain why adults process information faster and more efficiently than children do (Gaillard et al. 2011), and why the explicit system in children reaches its limits faster than the explicit system of adults (cf. Posner and Rothbart 2000).

A key component of the explicit system is cognitive control. It is responsible for overriding automatic impulses, and successful self-control (Munakata et al. 2012; Garon et al. 2008; Welsh and Pennington 1988). Cognitive control strongly develops throughout childhood and adolescence (for a review, see Garon et al. 2008). It is important to note, however, that this does not imply that younger children are not able to control their behaviour. Basic functions of cognitive control are already available from early childhood on, and the development of cognitive control reflects a developmental continuum (Garon et al. 2008; Lamm et al. 2006; Welsh and Pennington 1988).

The development of explicit processing is mapped in a fine-grained manner to children's processing of advertising in a model outlined by John (1999). The model proposes that children between 3 and 7 years old are "limited processors", who process advertising on a perceptual level. Between 7 and 11, children are "cued" processors. They are able to process commercials critically and systematically, but until adolescence still need assistance in doing 
so. From the age of 12 years, they are more competent "strategic processors", who posses the ability to process advertising adequately. The limitations in information processing capacity and executional control are also acknowledged by the recent approaches to advertising effects in children that we have reviewed above.

In contrast to the explicit system, the implicit system is a highly efficient module for information processing from early childhood on. The implicit system is independent from the functioning of higher-order brain structures (Reber 2013); as such, it is independent from the developmental pathways of these structures. A number of studies on implicit learning support the assumption that the implicit system works mostly independently from age (e.g. Meulemans et al. 1998; Saffran et al. 1997; Vinter and Perruchet 2000, 2002). Saffran et al. (1997), for instance, found that 6- and 7-year-old children showed the same performance as adults in the implicit learning of an artificial language. Recent results even indicate that children are more efficient than adults at learning implicitly (Janacsek et al. 2012).

\section{Dual Processes and Learning From Advertising}

Advertising effects affect behaviour mediated through learning. Since implicit processing involves different memory structures, exposure to advertising leads to specific learning processes. The implicit learning processes that are relevant for advertising effects are evaluative conditioning and associative learning (Shimp et al. 1991), and memory activation through mere exposure (Baker 1999; Zajonc 1968). It is important to note that most studies that have examined such implicit learning processes in relation to advertising have examined adult participants; however, the evidence referred to above (Janacsek et al. 2012) suggests that children will be affected by implicit learning to an even higher degree than adults. For instance, researchers have shown that conditioning effects can be observed in children from birth on (Sullivan et al. 1991).

Gibson (2008) studied the effects of evaluative conditioning on product choice under conditions of high or low cognitive load at the time of choice. During an exposure phase, the researcher paired positive or negative pictures with either Coke or Pepsi. He then measured explicit attitudes with a self-reported measure, and implicit attitudes with the implicit association test (IAT; Greenwald et al. 1998). He found that the conditioning procedure altered the implicit attitude, but not the explicit attitude (Study 1). Even more interestingly were the results for the product choice. Under conditions of high (but not low) cognitive load, the changes in the implicit attitude after the conditioning procedure correlated with choice for the positively conditioned brand (Study 2). Awareness of the contingencies for presented 
pairs of pictures was not necessary for the effect to occur (cf. Olson and Fazio 2001). If we take into account that children have a more limited cognitive capacity in explicit processing compared to adults, conditioning as demonstrated in Gibson's studies should significantly shape children's behaviour.

Mere exposure effects are not based on associations, but rather on the effects of previous activations (Grimes and Kitchen 2007). Consider the example of children who are exposed to a brand logo. It is likely that exposure to the brand logo will create implicit memory traces related to the physical features of the brand logo and associated semantic content. When the children perceive the $\log 0$ at a later point of time again, the memory traces are likely to be activated and to lead to perceptual fluency during the perception of the brand image when it is depicted in the same way as before. Perceptual fluency might further direct attention towards the brand, create responses of familiarity or positive affect, lead to inclusion into a consideration set, and finally affect choice.

Auty and Lewis (2004) studied mere exposure effects of advertising on children. They presented children with a scene from Home Alone. In the scene, Pepsi Cola appeared or did not appear. When children were exposed to Pepsi Cola in the scene, they were more likely to choose Pepsi over Coke during a later interview than when they were not exposed to Pepsi Cola. Interestingly, the study did not find a difference between younger (6-7 years) and older (11-12 years) children, which is in line with the age-invariance assumption in developmental research on implicit learning (e.g., Vinter and Perruchet 2000).

In a set of studies that examined the effects of mere exposure on perceptual fluency, consumers saw photos of people on a university campus (Ferraro et al. 2009). In the experimental conditions, the photos contained a bottle of branded water; in the control conditions, the bottle was not present. Afterwards, participants could choose out of four mineral waters as compensation for study participation. In line with the prediction, the authors found that participants who were exposed to the brand chose the brand more often, and the observed effect was stronger for participants who were not aware of the branded bottles in the photos, indicating the implicit nature of the effect. Furthermore, the researchers provided evidence that perceptual fluency contributes to the effect of brand exposure. When the researchers provided participants with a source to which they could attribute the perceptual fluency during choice, the effects of prior exposure declined.

Interestingly, mere exposure effects are not limited to perceptual fluency, but might also evoke conceptual fluency (Labroo et al. 2008). Conceptual fluency includes the more fluent processing of any material (and not only of a concrete stimulus like a brand logo as perceptual 
fluency) that matches the semantic network activated during exposure. Because younger children rely in particular on perceptual aspects of a brand, whereas older children rely more on conceptual or semantic aspects (Achenreiner and John 2003), it might be likely that the effects of brands as a conceptual primer that evokes fluency in the processing of a brand concept are stronger in older adults than in younger adults. However, as the studies of Ferraro et al. (2009) showed, brand logos can have effects at the perceptual level not only in children, but in adults as well.

\section{Dual Processes and Consumption Decisions}

One of the main aspects of the proposed model centres around the fact that explicit and implicit processes not only play a major role during exposure to advertising, but also when consumption decisions are made. Many undesirable consumption decisions involve selfcontrol conflict (Hoch and Loewenstein 1991). On the one hand, children may have the immediate impulse to give in to a temptation, such as eating a chocolate bar, buying ice cream, or pestering their parents to buy them an attractive toy. On the other hand, children may also hold goals to control this impulse. These goals may be internal, for instance when children have a goal to save money for a higher good, such as a new musical instrument. In addition, self-control goals may be external goals that are held by the parents. Children may be aware, for instance, that the parents want them to eat healthy food instead of chocolate, or that they do not appreciate the pestering.

According to the reflective-impulsive model set forth by Strack and Deutsch (2004; see also Strack et al. 2006), such self-control conflicts involve the interplay between explicit and implicit processes. In the model, implicit processes are referred to as impulsive precursors of behaviour, which can be overridden by explicit processes if individuals possess the necessary capacity. The model proposes that implicit processes already affect attention and impulses (Büttner et al. 2013). It assumes that the recognition of a brand (e.g., seeing a brand of soft drink) will activate the cognitive representations (e.g., sweetness) that have been linked to this brand (e.g., by previous advertising). If these representations are positive, this is assumed to elicit an approach tendency towards the brand, and also to activate related motor programmes for approach (Genschow et al. 2013) and a strong purchase impulse (Hubert et al. 2013). The model supposes that impulses can directly lead to behaviour, but that they can also be overwritten by the explicit system (Florack et al. 2010; Florack and Scarabis 2006; Hubert et al. 2013; Scarabis et al. 2006). 
Several approaches imply that three factors contribute to whether explicit self-control dominates in a self-control conflict (Fazio and Towles-Schwen 1999; Hofmann et al. 2009; Muraven and Baumeister 2000): (a) the strength of the activated impulse, (b) the existence of a self-control goal and self-control motivation, and (c) the self-regulatory capacity. The strength of the impulse is partly influenced by previous advertising, that is, it is influenced during Step 1 (ad exposure) of our model. The impulse is stronger when children have formed memory structures that link the product with positive associations. Importantly, implicit influences of advertising such as perceptual fluency are supposed to strongly influence the strength of the impulse. The self-control goal can either be chosen by the child or imposed by parents or other significant others. The self-regulatory capacity refers to the child's ability to effectively deal with the self-control conflict and to pursue the self-control goal during the consumption decision.

A series of classic studies by Mischel and colleagues have provided impressive examples for the self-control conflict in children (e.g., Mischel and Ebbesen 1970; Mischel and Mischel 1983). In a typical study within this series, the children were seated at a table with a marshmallow in front of them. An experimenter told them that she would leave the room, and that the children would receive a second marshmallow if they did not eat the one on the table until the experimenter returned. The experimenter then left the room, and the researches observed whether the children waited for the return of the experimenter to eat the marshmallow. For most children, the task was very difficult even though they had in mind the prospect of the reward after the return of experimenter.

Interestingly, even in the classic studies by Mischel and colleagues, there was considerable variance in self-control success between children and between different experimental conditions (Mischel and Mischel 1983). Also, other studies report individual differences in self-control (Moffitt et al. 2011; Vazsonyi and Huang 2010). Wills et al. (2010), for instance, found that alcohol and tobacco advertising had lower effects on the willingness to consume (Study 1) or the actual consumption (Study 2) of children with high self-control than of those with low self-control. Indeed, basic mechanisms of effortful control emerge in children as early as between 6 and 12 months of age (Diamond 1991). Hence, even though there is a correlation between age and self-control (Kochanska et al. 1996; Vaszonyi and Huang 2010), which is partly caused by the development of the brain (e.g., Garon et al. 2008; Welsh and Pennington 1988), this does not mean that children cannot perform self-control. Indeed, there are a number of training schemes designed to significantly increase self-control in children (Diamond and Lee 2011; Piquero et al. 2010). 


\section{Self-regulation as a Defence Against the Implicit Effects of Advertising}

Since advertising alters implicit preferences, and implicit preferences drive behaviour at a time when children do not recall the advertising, strengthening children's self-regulation capabilities in such a way that they are effective at the time of consumption seems to be a fruitful way in which to mitigate the negative influence of advertising on children's consumption decisions. However, the basic question arises of how such self-regulatory strategies can help to prevent undesired effects of advertising.

At first glance, the research reviewed above draws a pessimistic picture of the selfcontrol abilities of children. The research illustrates that self-control is difficult for younger children (Kochanska et al. 1996; Vaszonyi and Huang 2010), and that brain structures that support successful self-regulation are less developed in younger children than in adults (Casey et al. 2008; Sowell et al. 1999). However, we should not disregard the idea that there are possibilities for control beyond the effortful cognitive self-control on the explicit level that we reviewed above. Recent research has demonstrated that self-control can be automatized and driven by implicit processes (for an overview, see Dewitte 2013). In the same way as children can learn to avoid crossing a street when the lights are red, they can learn to avoid buying unhealthy food or pestering their parents to buy expensive toys, and they can learn to develop alternative behaviour to purchase requests.

Implicit Self-Control

There are two mechanisms by which implicit processes can support self-control: By the automatic activation of self-control goals, and by automatically shielding goal pursuit from attractive temptations. Self-control goals can operate via implicit processes (Bargh et al. 2001; Ferguson and Bargh 2004; Fitzsimons et al. 2008). They can be automatically activated by temptations (Fishbach et al. 2003) or by situational cues (Fitzsimons and Finkel 2010; Gollwitzer and Sheeran 2006). Successful self-regulators, for instance, are likely to activate a control goal automatically when they perceive a temptation (Fishbach et al. 2003). Thus, perceiving palatable but unhealthy food can evoke the goal of eating healthy food.

The behaviour (Mau et al. 2012) and the mere presence of parents or other persons relevant for self-regulation (Fitzsimons and Finkel 2010) can activate self-control goals. Mau et al. (2012) found, for instance, that if an adult stated that soft drinks are unhealthy, children making a choice between different beverages chose the soft drink less often. Fitzsimons and Finkel (2010) found that the imagined presence of other persons also affects the activation of 
self-control goals. Experiments that solely "reminded" participants at other persons (e.g., the father) via subliminal priming produced similar effects (Shah 2003).

The activation of control goals is a first step to prevent undesired effects of advertising on behaviour. However, this step will be not sufficient if implementing control is still based on self-regulatory resources and competences. Hence, it is important that self-control goals can automatically inhibit the activation of temptations. Fishbach et al. (2003), for instance, found evidence for such associations between self-control goals and temptations that are asymmetric, and facilitate successful self-control: A temptation (e.g., a perception of unhealthy food) can automatically activate associated self-control goals (e.g., eating healthily), while the self-control goals inhibit the activation of temptation goals. Thus, a possibility to establish self-control on an implicit level would be to establish associations between temptations and control goals in such a way that thinking about an immediate temptation (e.g., buying sweets) activates a relevant self-control goal (e.g., saving money for a musical instrument), while thinking about the self-control goal does not activate thoughts about the temptation. A key characteristic of such activation patterns is that they facilitate successful goal pursuit, while at the same time they do not require cognitive resources. Thus, they do not require cognitive capacity or cognitive control on the level of the explicit system.

Besides the activation of control goals, goal shielding can prevent temptation from being activated in memory. If individuals pursue a particular goal, competing goals are often automatically inhibited in memory (Shah et al. 2002); these automatic inhibitions of competing goals facilitate goal pursuit, because they prevent individuals from engaging in thinking about other goals instead of focusing on the goal they are carrying out at the moment. In addition to the inhibition of competing goals, pursuing a particular goal also narrows individuals' focus of attention, and individuals pursuing a specific goal are less likely to get distracted by irrelevant stimuli (Fujita et al. 2007).

The abovementioned research on asymmetric associations between temptations and control goals and research on goal shielding has mainly studied adult participants. Based on the finding that the functionality of the implicit system is already available in younger children (e.g., Janacsek 2012), we assume that these mechanisms of implicit self-control apply to children as well. Indeed, recent research shows the potential of methods that establish goal shielding on an implicit level (Gawrilow and Gollwitzer 2008; Gawrilow et al. 2011a, b; Wieber et al. 2011). 


\section{From Explicit to Implicit Self-Control}

When we consider the research showing that implicit self-control is possible, it is important to think about techniques that help to establish self-control on an implicit level. In our view, three techniques are particularly suitable to pursue this goal: (a) setting goals, (b) learning through imitation, and (c) forming implementation intentions. Since parents or other primary caregivers are a main source for learning successful self-control (cf. Vazsonyi and Huang 2010), and are the most likely persons to accompany children in shopping situations, we partly explain these techniques with reference to these caregivers below.

\section{Setting Goals}

Self-control goals are the starting point for self-control, and are initially explicit. In Mischel and colleagues' classical experiments referred to above (Mischel and Ebbesen 1970; Mischel et al. 1972), the self-control goal for the participants was to wait until the experimenter returned before eating the marshmallow. The goal was activated via the explicit instruction of the experimenter. This is comparable with a situation in which parents tell their children in a supermarket that, for instance, they should refrain from taking products off of the shelves. Self-control goals might also be activated in a more playful way, for instance by making up a game: "Today, we are going to try and buy healthy food from the present season". While parents might first set a goal on an explicit level, the goal activation can become more and more automatic over time. For example, parents might activate the goal on first entering the supermarket. Later, children might activate the goal by just thinking about their parents when they enter a supermarket. Finally, just entering a supermarket might activate the goal.

Instead of activating a self-control goal, parents could also evoke alternative goals in their children, for instance to find a particular product. Since pursuing focal goals inhibits the activation of alternative tempting goals (Shah et al. 2002), and narrows the focus of attention (Fujita et al. 2007), children who pursue a particular goal while they are shopping with their parents can be supposed to be less likely to think about tempting products, and to notice these products. These goal-related processes could easily be applied as a technique for strengthening children's self-control during shopping. When, for instance, children are asked to find a certain product (e.g., milk), goal shielding and a narrowed focus of attention should make them less vulnerable to tempting stimuli in the supermarket. Importantly, it is not just parents that can set such goals. Depending on the age of the children, as well as family structures and communication patterns (Ekström 2010; Kline 2011), families may differ in the degree to which children are involved in the process of goal setting. For instance, parents 
from families with a consensual communication pattern may involve their children in the process of goal setting more than parents who favour a protective communication pattern and thus set the goals.

\section{Imitation}

Children learn in a natural manner every day from birth on. A key mechanism of learning is imitation, and, in particular, imitation of parents' behaviour (Bandura 1977; Bandura and Walters 1963). Individuals acquire skills - including strategies to manage challenges - through observing behaviour (Bandura 1997). Accordingly, parents have an important influence on purchase intentions and behaviour (Martin and Bush 2000). Thus, children can enhance self-control by observing their parents when they engage in self-control, such as ignoring tempting ice cream and eating an apple instead.

Furthermore, parents form values in children through behaviour and engagement in tasks and choices, and expressed attitudes (Jacobs and Eccles 2000). For instance, if children perceive their parents as having a brand preference, they might imitate the behaviour and develop positive attitudes toward the brand. Similarly, if parents' shopping behaviour reflects a critical position towards advertising messages at the point of purchase, children might develop advertising scepticism as well.

It is clear that implicit processes of self-control do not develop by observing one instance of parental behaviour, but need repeated instances. In addition, children need to perform self-control by themselves in order to automatize behaviour. However, interestingly, research on self-control shows that self-control in one domain is often associated with selfcontrol in other domains (Moffitt et al. 2011; Piquero et al. 2010; Shoda et al. 1990). Hence, it is likely that establishing self-control in one domain spreads to self-control in others. Recent research shows that self-control training could have such spreading effects (Diamond and Lee 2011).

\section{Implementation Intentions}

Besides being a model for children or providing them with tasks to teach goals and/or fostering goal shielding, parents could apply implementation intentions as a promising technique to shape children's responses to products. Research has found that implementation intentions are very effective tools in automatizing self-control (Gollwitzer 1999; Gollwitzer and Oettingen 2011). Basically, implementation intentions are if-then plans: Individuals specify a condition (if) under which they intend to exhibit a particular behaviour (then). A 
simple implementation intention is: "If I see a sugared soft drink, I buy mineral water". Implementation intentions have been found to be more effective than simple goal intentions (e.g., "I want to live healthily").

Implementation intentions are a technique for delegating action control to the implicit system. An implementation intention is formed by the explicit system via thinking and planning, but the execution operates at an implicit, automatic level (Gollwitzer and Sheeran 2009). Two mechanisms support the effects of implementation intentions (Gollwitzer and Sheeran 2009). First, the "if"-part is chronically accessible in memory; that is, individuals are faster at detecting the situation that requires the execution of the "then" part (Aarts et al. 1999). Second, forming an implementation intention builds a strong representation in memory between the "if" and the "then" component (Webb and Sheeran 2007). Thus, activating the "if" component (e.g., seeing a soft drink in the supermarket) automatically activates the "then" part (e.g., taking a bottle of mineral water). The automaticity of implementation intentions provides a major benefit of self-control: Implementation intentions also work when self-control resources are depleted (Webb and Sheeran 2003).

A large body of research has found that the simple technique of forming implementation intentions is a highly effective tool to ensure successful goal pursuit. In a meta-analysis of 94 studies that examined the effectiveness of implementation intentions, Gollwitzer and Sheeran (2006) found an overall effect size of $d=.65$, which denotes a medium-to-large effect. Implementation intentions were successful across a wide array of self-control domains, such as eating a low-fat diet (Armitage 2004), athletic goals (Achtziger et al. 2008), or academic test performance (Bayer and Gollwitzer 2007).

Importantly, implementation intentions have also been found to work well for children. Implementation intentions help children to ignore attractive distractions (Wieber et al. 2011), increase performance in a go/no-go task (Gawrilow and Gollwitzer 2008), enhance the ability to delay gratifications (Gawrilow et al. 2011a), and facilitate shifting between tasks (Gawrilow et al. 2011b). Interestingly, implementation intentions also helped to establish selfcontrol in children who had been diagnosed with attention deficit hyperactivity disorder (ADHD), a problem that goes along with highly impulsive behaviour (Gawrilow and Gollwitzer 2008; Gawrilow et al. 2011a, b).

Wieber et al. (2011) argue that younger children in particular will benefit from implementation intentions, because they are less likely to form plans by themselves and possess less self-control skills than older children. This points to an important aspect of using 
implementation intentions: Children need to be supported by their parents, or other caregivers, to form corresponding implementation intentions.

To illustrate the technique of implementation intentions, think of a child who wants to save his or her pocket money for a higher goal (e.g., a new musical instrument) instead of spending it on sweets. This child might form an implementation intention such as "If I pass a shelf with sweets in the supermarket, I will ignore them". Instead of simply ignoring the distracting stimulus, the then-part could also specify a focus on the higher goal: "If I pass a shelf with sweets, I will think about the musical instrument that I will buy with my pocket money". Moreover, the then-part could also specify an alternative action. For instance, "If I see a soft drink in the supermarket, I will buy a bottle of mineral water" could be an implementation intention that aims at drinking fewer soft drinks.

\section{Conclusion and Implications for Consumer Policy}

Our review of the current state of research shows that implicit processes contribute significantly to the influence of advertising beyond explicit processes on the conscious level of self-control, and that persuasion knowledge and media literacy are not enough to prevent or reduce undesired advertising effects. Even if children are fully aware of the influence of advertising during exposure, numerous implicit advertising effects can influence their behaviour in consumption and purchasing contexts. In this respect, strong regulations for advertising to children seem to be needed, and, indeed, a number of countries have applied such measures (Calvert 2008; Mitchell 1998; The Henry J. Kaiser Family Foundation 2004). However, it is evident that legislation will not solve the problem. Advertising is ubiquitous in modern consumer societies, and children will nevertheless be confronted with marketing communications that are designed for adults, but will influence children's behaviour as well. Therefore, we take the position that the most promising way to mitigate undesired advertising effects on children is to teach media literacy (or, even better, advertising and purchasing literacy), and to complement this approach by shaping effective self-regulation strategies in purchase and consumption settings (see Figure 2).

\section{XXXXX INSERT FIGURE 2 XXXXX}

\section{Advertising and Purchasing Literacy}

As outlined at the beginning of this article, strengthening children's media literacy and persuasion knowledge has been an influential approach in research on children and 
advertising (Austin and Johnson 1997; Roberts et al. 1980; Wright et al. 2005). Training that increases children's media literacy and persuasion knowledge (see, e.g., Austin and Johnson 1997; Roberts et al. 1980) can easily be implemented in preschools and schools. We recommend that such training includes persuasion knowledge on marketing tactics that are employed in advertising and in-store settings. This specific persuasion knowledge could be termed "advertising and purchasing literacy". Previous research has collected an impressive amount of findings regarding how point-of-purchase marketing influences consumer decisions (e.g., Ailawadi et al. 2009; Turley and Milliman 2000). Knowledge about such tactics could help children to (partly) immunize themselves against in-store promotions, as could knowledge about advertising techniques according to the immediate effects of advertising exposure (Roberts et al. 1980). Moreover, training on advertising and purchasing literacy might ideally contain knowledge about consumer decision-making and financial skills (see Kline 2010, on the concept of consumer literacy and economic literacy).

Teaching advertising and purchasing literacy would extend the traditional media literacy approach, as it considers consumption decisions to be made in situations other than during ad exposure. This is also in line with Kline's (2010) call for extending the focus on children's competencies by taking into account consumer literacy and economic literacy.

\section{Strengthening Children's Implicit Self-Regulatory Competencies}

Strengthening children's implicit self-regulatory competencies is an additional way to limit the undesired impact of advertising at the implicit level. Self-regulatory competencies help children to control the impulses that ad-based memory structures elicit (enhancement of selfcontrol), and to direct their motivation and attention towards alternatives or higher-order goals (directing self-regulation).

We have outlined three ways in which implicit self-regulation can be fostered. First, parents should set goals - either self-control goals or alternative goals that children can pursue during shopping situations. The implicit mechanisms of goal shielding (Shah et al. 2002) and a narrowed focus of attention (Fujita et al. 2007) that follow from goal pursuit should reduce the likelihood that children will think about and notice tempting products.

Third, observing parents' behaviour can be regarded as an important mechanism by which to develop associations between temptations and self-control, but also to learn selfcontrol in a more general manner (Martin and Bush 2000).

Fourth, self-control can be delegated to the implicit system by the simple but effective technique of forming implementation intentions (Gollwitzer 1999; Gollwitzer and Oettingen 
2011). The formulation of if-then plans that specify a condition (if-part) under which one intends to engage in a particular behaviour (then-part) is one of the most promising techniques by which to obtain impressive effects in short amounts of time (Wieber et al. 2011).

An important question for consumer policy is how, and at what level, training that aims to increase children's implicit self-regulatory competencies could be employed. The preschool and school settings appear to be only partially adequate in this regard. As outlined above, self-control competencies should be learned, and will be applied in shopping and consumption situations where parents are the most likely persons to accompany their children. In addition, parenting is an important factor that contributes to successful self-control in children (Vazsonyi and Huang 2010). This implies that any programmes that aim to strengthen children's self-control in purchase situations needs to address the parents. Such a programme should educate parents about the need to strengthen children's implicit selfcontrol, and about techniques of how this can be achieved. Parents, however, differ in the degree to which they are able and willing to actively engage in the consumer socialisation of their children (Ekström 2010; Kline 2011). Thus, the implementation of such a programme would need to account for differences between families, such as family structure, communication patterns, and various types of socio-economic resources.

Overall, self-control is an important factor that contributes to individuals' wellbeing and success in various domains (for a meta-analysis, see de Ridder et al. 2012). Importantly, selfcontrol during childhood predicts success during later phases in life. Studies using Mischel and colleagues' classic marshmallow paradigm (Shoda et al. 1990; see also Moffitt et al. 2011) showed that the longer the children were able to resist the temptation to eat the marshmallow when they were 6 years old, the higher was their academic competence and ability to cope with stress and frustration when they were 15-18 years old. Thus, increasing children's self-control competences may also provide benefits that go far beyond reducing the negative effects of advertising.

\section{References}

Aarts, H., Dijksterhuis, A., \& Midden, C. (1999). To plan or not to plan? Goal achievement or interrupting the performance of mundane behaviors. European Journal of Social Psychology, 29, 971-979.

Achenreiner, G. B., \& John, D. R. (2003). The meaning of brand names to children: A developmental investigation. Journal of Consumer Psychology, 13(3), 205-219. 
Achtziger, A., Gollwitzer, P. M., \& Sheeran, P. (2008). Implementation intentions and shielding goal striving from unwanted thoughts and feelings. Personality and Social Psychology Bulletin, 34(3), 381-393.

Ailawadi, K. L., Beauchamp, J. P., Donthu, N., Gauri, D. K., \& Shankar, V. (2009). Communication and promotion decisions in retailing: A review and directions for future research. Journal of Retailing, 85(1), 42-55.

Anschutz, D. J., Engels, R. C. M. E., \& Van Strien, T. (2012). Increased body satisfaction after exposure to thin ideal children's television in young girls showing thin ideal internalisation. Psychology \& Health, 27(5), 603-617.

Anschutz, D. J., Spruijt-Metz, D., Van Strien, T., \& Engels, R. C. M. E. (2011). The direct effect of thin ideal focused adult television on young girls' ideal body figure. Body Image, 8(1), 26-33.

Armitage, C. J. (2004). Evidence that implementation intentions reduce dietary fat intake: A randomized trial. Health Psychology, 23(3), 319-323.

Austin, E. W., \& Johnson, K. K. (1997). Immediate and delayed effects of media literacy training on third grader's decision making for alcohol. Health Communication, 9(4), $323-349$.

Auty, S. \& Lewis, C. (2004). Exploring children's choice: The reminder effect of product placement. Psychology and Marketing, 21(9), 697-713.

Baker, W. E. (1999). When can affective conditioning and mere exposure directly influence brand choice? Journal of Advertising, 28(4), 31-46.

Baker, W. E., \& Lutz, R. J. (1988). The relevance-accessibility model of advertising effectiveness. In S. Hecker \& D. W. Stewart (Eds.), Nonverbal Communication in Advertising (pp. 59-84). Lexington MA: Lexington Books.

Baker, W. E., \& Lutz, R. J. (2000). An empirical test of an updated relevance-accessibility model of advertising effectiveness. Journal of Advertising, 29(1), 1-14.

Bandura, A. (1977). Social learning theory. Oxford, England: Prentice-Hall.

Bandura, A. (1997). Self-efficacy: The exercise of control. New York, NY: Freeman.

Bandura, A., \& Walters, R. H. (1963). Social learning and personality development. New York, NY: Holt, Rinehart and Winston.

Bargh, J., Gollwitzer, P., Lee-Chai, A., Barndollar, K., \& Trotschel, R. (2001). The automated will: Nonconscious activation and pursuit of behavioral goals. Journal of Personality and Social Psychology, 81(6), 1014-1027. 
Barrouillet, P. (2011). Dual-process theories of reasoning: The test of development. Developmental Review, 31(2-3), 151-179.

Bayer, U. C., \& Gollwitzer, P. M. (2007). Boosting scholastic test scores by willpower: The role of implementation intentions. Self and Identity, 6, 1-19.

Bijmolt, T. H. A., Claassen, W., \& Brus, B. (1998). Children's understanding of TV advertising: Effects of age, gender, and parental influence. Journal of Consumer Policy, 21(2), 171-194.

Brown, J. (2001). Media literacy and critical viewing in education. In D. Singer \& J. Singer (Eds.), Handbook of children and the media (pp. 681-698). Thousand Oaks, CA: Sage Publications.

Brucks, M., Armstrong, G. M., \& Goldberg, M. E. (1988). Children's use of cognitive defenses against television advertising: A cognitive response approach. Journal of Consumer Research, 14(4), 471-482.

Buckingham, D. (2007). Selling childhood? Journal of Children and Media, 1(1), 15-24.

Buckingham, D. (2009). Beyond the competent consumer: the role of media literacy in the making of regulatory policy on children and food advertising in the UK. International Journal of Cultural Policy, 15(2), 217-230.

Buijzen, M., \& Valkenburg, P. M. (2003). The unintended effects of television advertising: A parent-child survey. Communication Research, 30(5), 483-503.

Buijzen, M., \& Valkenburg, P. M. (2008). Observing purchase-related parent-child communication in retail environments: A developmental and socialization perspective. Human Communication Research, 34(1), 50-69.

Buijzen, M., Van Reijmersdal, E. A., \& Owen, L. H. (2010). Introducing the PCMC Model: An investigative framework for young people's processing of commercialized media Content. Communication Theory, 20(4), 427-450.

Büttner, O., Florack, A., Leder, H., Paul, M., Serfas, B., \& Schulz, A. M. (2013). Hard to ignore: impulsive buyers show an attentional bias in shopping situations. Social Psychological and Personality Science. Advance online publication. doi:10.1177/1948550613494024

Calvert, S. L. (2008). Children as consumers: Advertising and marketing. Future of Children, $18(1), 205-234$.

Casey, B., Galvan, A., \& Hare, T. A. (2005). Changes in cerebral functional organization during cognitive development. Current Opinion in Neurobiology, 15(2), 239-244.

Casey, B. J., Getz, S., \& Galvan, A. (2008). The adolescent brain. Developmental Review, 
28(1), 62-77.

Dennison, B. A., Russo, T., Burdick, P., \& Jenkins, P. (2004). An intervention to reduce television viewing by preschool children. Archives of Pediatrics \& Adolescent Medicine, 158(2), 170.

de Ridder, D. T., Lensvelt-Mulders, G., Finkenauer, C., Stok, F. M., \& Baumeister, R. F. (2012). Taking stock of self-control: A meta-analysis of how trait self-control relates to a wide range of behaviors. Personality and Social Psychology Review, 16(1), 76-99.

Desrochers, D. M., \& Holt, D. J. (2007). Children's exposure to television advertising: Implications for childhood obesity. Journal of Public Policy \& Marketing, 26(2), 182201.

Dewitte, S. (2013). From willpower breakdown to the breakdown of the willpower model The symmetry of self-control and impulsive behavior. Journal of Economic Psychology. $38,16-25$.

Diamond, A. (1991). Neuropsychological insights into the meaning of object concept development. In S. Carey \& R. Gelman (Eds.), The epigenesis of mind: Essays on biology and cognition (pp. 67-110). Hillsdale, England: Lawrence Erlbaum.

Diamond, A., \& Lee, K. (2011). Interventions shown to aid executive function development in children 4 to 12 years old. Science, 333(6045), 959-964.

Edin, F., Macoveanu, J., Olesen, P., Tegnér, J., \& Klingberg, T. (2007). Stronger Synaptic Connectivity as a Mechanism behind Development of Working Memory-related Brain Activity during Childhood. Journal of Cognitive Neuroscience, 19(5), 750-760.

Ekström, K. M. (2010). Consumer Socialization in Families. In D. Marshall (Ed.), Understanding childran as consumers (pp. 41-60). London: Sage Publications.

Elements of Art GmbH, iconkids \& youth, SUPER RTL, \& IP Deutschland (2010). Die Lieblings-Websites der Kids - Entstehung, Zusammensetzung und Entwicklung des Relevant Set im Internet. Mönchengladbach/München.

Evans, J. S. B. T. (2008). Dual-processing accounts of reasoning, judgment, and social cognition. Annual Review of Psychology, 59(1), 255-278.

Fang, X., Singh, S., \& Ahluwalia, R. (2007). An examination of different explanations for the mere exposure effect. Journal of Consumer Research, 34(1), 97-103.

Fazio, R. H., \& Towles-Schwen, T. (1999). The MODE model of attitude-behavior processes. In S. Chaiken \& Y. Trope (Eds.), Dual-process Theories in Social Psychology (pp. 97116). New York, NY: Guilford Press.

Feierabend, S. \& Klingler, W. (2012). Was Kinder sehen. Media Perspektiven, 4/2012, 203 - 
214.

Ferguson, M. J., \& Bargh, J. A. (2004). Liking is for doing: The effects of goal pursuit on automatic evaluation. Journal of Personality and Social Psychology, 87, 557-572.

Ferraro, R., Bettman, J. R., \& Chartrand, T. L. (2009). The power of strangers: The effect of incidental consumer brand encounters on brand choice. Journal of Consumer Research, $35(5), 729-741$.

Fishbach, A., Friedman, R. S., \& Kruglanski, A. W. (2003). Leading us not into temptation: Momentary allurements elicit overriding goal activation. Journal of Personality and Social Psychology, 84(2), 296-309.

Fitzsimons, G. M., Chartrand, T. L., \& Fitzsimons, G. J. (2008). Automatic effects of brand exposure on motivated behavior: How Apple makes you think different. Journal of Consumer Research, 35(1), 21-35.

Fitzsimons, G. M., \& Finkel, E. J. (2010). Interpersonal influences on self-regulation. Current Directions in Psychological Science, 19(2), 101-105.

Florack, A., Friese, M., \& Scarabis, M. (2010). Regulatory focus and reliance on implicit preferences in consumption contexts. Journal of Consumer Psychology, 20(2), 193-204.

Florack, A., Piontkowski, U., Knocks, I., Rottmann, J., \& Thiemann, P. (2002). Attitude change: The case of attitudes towards the "green card" in Germany. Current Research in Social Psychology, 8(3).

Florack, A., \& Scarabis, M. (2006). How advertising claims affect brand preferences and category-brand associations: The role of regulatory fit. Psychology and Marketing, 23(9), 741-755.

Frank, M. J., Cohen, M. X., \& Sanfey, A. G. (2009). Multiple systems in decision making: A neurocomputational perspective. Current Directions in Psychological Science, 18(2), $73-77$.

Frank, M. J., O’Reilly, R. C., \& Curran, T. (2006). When memory fails, intuition reigns: Midazolam enhances implicit inference in Humans. Psychological Science, 17(8), 700707.

Friestad, M., \& Wright, P. (1994). The persuasion knowledge model: How people cope with persuasion attempts. Journal of Consumer Research, 21(1), 1-31.

Fujita, K., Gollwitzer, P. M., \& Oettingen, G. (2007). Mindsets and pre-conscious openmindedness to incidental information. Journal of Experimental Social Psychology, 43(1), 48-61.

Gaillard, V., Barrouillet, P., Jarrold, C., \& Camos, V. (2011). Developmental differences in 
working memory: Where do they come from? Journal of Experimental Child Psychology, 110(3), 469-479.

Galst, J. P., \& White, M. A. (1976). The unhealthy persuader: The reinforcing value of television and children's purchase-influencing attempts at the supermarket. Child Development, 47(4), 1089.

Gantz, W., Schwartz, N., \& Angelini, J. R. (2007). Television Food Advertising to Children in the United States (Kaiser Family Foundation Report). Retrieved from http://faculty.ithaca.edu/jpowers/docs/SenSemReadings/foodforthought.pdf

Garon, N., Bryson, S. E., \& Smith, I. M. (2008). Executive function in preschoolers: A review using an integrative framework. Psychological Bulletin, 134(1), 31-60.

Gawrilow, C., \& Gollwitzer, P. M. (2008). Implementation intentions facilitate response inhibition in children with ADHD. Cognitive Therapy and Research, 32(2), 261-280.

Gawrilow, C., Gollwitzer, P. M., \& Oettingen, G. (2011a). If-then plans benefit delay of gratification performance in children with and without ADHD. Cognitive Therapy and Research, 35(5), 442-455.

Gawrilow, C., Gollwitzer, P. M., \& Oettingen, G. (2011b). If-then plans benefit executive functions in children with ADHD. Journal of Social and Clinical Psychology, 30(6), 616-646.

Genschow, O., Florack, A., Chib, V., Shimojo, S., Scarabis, M., \& Wänke, M. (2013). Reaching for the (product) stars: Measuring recognition and approach speed to get insights into consumer choice. Basic and Applied Social Psychology, 35, 298-315

Gibson, B. (2008). Can evaluative conditioning change attitudes toward mature brands? New evidence from the implicit association test. Journal of Consumer Research, 35(1), 178188.

Giedd, J. N., Snell, J. W., Lange, N., Rajapakse, J. C., Casey, B. J., Kozuch, P. L., ... Rapoport, J. L. (1996). Quantitative Magnetic Resonance Imaging of Human Brain Development: Ages 4-18. Cerebral Cortex, 6(4), 551-559.

Gillig, P. M., \& Greenwald, A. G. (1974). Is it time to lay the sleeper effect to rest? Journal of Personality and Social Psychology, 29(1), 132-139.

Goldberg, M. E., \& Gorn, G. J. (1978). Some unintended consequences of TV advertising to children. Journal of Consumer Research, 5(1), 22-29.

Gollwitzer, P. M. (1999). Implementation intentions. American Psychologist, 54(7), 493-503. Gollwitzer, P. M., \& Oettingen, G. (2011). Planning promotes goal striving. In K. D. Vohs \& R. F. Baumeister (Eds.), Handbook of self-regulation: Research, theory, and 
applications (2nd ed., pp. 162-185). New York: Guilford Press.

Gollwitzer, P. M., \& Sheeran, P. (2006). Implementation intentions and goal achievement: A meta-analysis of effects and processes. Advances in Experimental Social Psychology, $38,69-119$.

Gollwitzer, P. M., \& Sheeran, P. (2009). Self-regulation of consumer decision making and behavior: The role of implementation intentions. Journal of Consumer Psychology, 19(4), 593-607.

Graff, S., Kunkel, D., \& Mermin, S. E. (2012). Government can regulate food advertising to children because cognitive research shows that it is inherently misleading. Health Affairs, 31(2), 392-398.

Greenwald, A. G., McGhee, D. E., \& Schwartz, J. L. K. (1998). Measuring individual differences in implicit cognition: The implicit association test. Journal of Personality and Social Psychology, 74(6), 1464-1480.

Grimes, A., \& Kitchen, P. J. (2007). Researching mere exposure effects to advertising. Theoretical foundations and methodological implications. International Journal of Market Research, 49(2), 191-219.

Grunert, K. G. (1994). Cognition and economic psychology. In H. Brandstatter \& W. Guths (Eds.), Essays in Economic Psychology (pp. 91-108). Berlin: Springer-Verlag.

Hang, H., \& Auty, S. (2011). Children playing branded video games: The impact of interactivity on product placement effectiveness. Journal of Consumer Psychology, 21(1), 65-72.

Harris, J. L., Bargh, J. A., \& Brownell, K. D. (2009a). Priming effects of television food advertising on eating behavior. Health Psychology, 28(4), 404-413.

Harris, J. L., Brownell, K. D., \& Bargh, J. A. (2009b). The food marketing defense model: Integrating psychological pesearch to protect youth and inform public policy. Social Issues and Policy Review, 3(1), 211-271.

Hastings, G., Stead, M., McDermott, L., Forsyth, A., MacKintosh, A. M., Rayner, M., ... Angus, K. (2003). Review of research on the effects of food promotion to children (Food Standards Agency Report). Retrieved from http://www.food.gov.uk/multimedia/pdfs/foodpromotiontochildren1.pdf

Hoch, S. J., \& Loewenstein, G. F. (1991). Time inconsistent preferences and consumer selfcontrol. Journal of Consumer Research, 17(4), 492-507.

Hofmann, W., Friese, M., \& Strack, F. (2009). Impulse and self-control from a dual-systems perspective. Perspectives on Psychological Science, 4(2), 162-176. 
Hovland, C. I., \& Weiss, W. (1951). The influence of source credibility on communication effectiveness. Public Opinion Quarterly, 15(4), 635-650.

Hubert, M., Hubert, M., Florack, A., Linzmajer, M., \& Kenning, P. (2013). Neural correlates of impulsive buying tendencies during the perception of product packages. Psychology and Marketing, 30, 861-873.

Jacobs, J. E., \& Eccles, J. S. (2000). Parents, task values, and real-life achievement-related choices. In C. Sansone \& J. M. Harackiewicz (Eds.), Intrinsic and Extrinsic Motivation: The Search for Optimal Motivation and Performance (pp. 405-439). San Diego, CA: Academic Press.

Janacsek, K., Fiser, J., \& Nemeth, D. (2012). The best time to acquire new skills: age-related differences in implicit sequence learning across the human lifespan. Developmental Science, 15(4), 496-505.

John, D. R. (1999). Consumer socialization of children: A retrospective look at twenty-five years of research. Journal of Consumer Research, 26(3), 183-213.

Kahneman, D. (2003). Maps of bounded rationality: Psychology for behavioral economics. American Economic Review, 93(5), 1449-1475.

Karrh, J. A. (1998). Brand placement: A review. Journal of Current Issues \& Research in Advertising, 20(2), 31-49.

Kline, S. (2010). Children as competent consumers. In D. Marshall (Ed.), Understanding childran as consumers (pp. 239-257). London: Sage Publications.

Kline, S. (2011). Globesity, food marketing and family lifestyles. Basingstoke, Hampshire ; New York: Palgrave Macmillan.

Kochanska, G., Murray, K., Jacques, T. Y., Koenig, A. L., \& Vandegeest, K. A. (1996). Inhibitory control in young children and its role in emerging internalization. Child Development, 67(2), 490-507.

Kumkale, G. T., \& Albarracín, D. (2004). The sleeper effect in persuasion: A meta-analytic review. Psychological Bulletin, 130(1), 143-172.

Kunkel, D., Wilcox, B. L., Cantor, J., Palmer, E., Linn, S., \& Dowrick, P. (2004). Report of the APA task force on advertising and children (No. 40). American Psychological Association. Retrieved from http://www.sfu.ca/cmns/faculty/kline_s/320/06spring/resources/sup_readings/childrenads.pdf

Labroo, A. A., Dhar, R., \& Schwarz, N. (2008). Of frog wines and frowning watches: Semantic priming, perceptual fluency, and brand evaluation. Journal of Consumer Research, 34(6), 819-831. 
Lamm, C., Zelazo, P. D., \& Lewis, M. D. (2006). Neural correlates of cognitive control in childhood and adolescence: Disentangling the contributions of age and executive function. Neuropsychologia, 44(11), 2139-2148.

Livingstone, S., \& Helsper, E. J. (2006). Does advertising literacy mediate the effects of advertising on children? A critical examination of two linked research literatures in relation to obesity and food choice. Journal of Communication, 56(3), 560-584.

Martin, C. A., \& Bush, A. J. (2000). Do role models influence teenagers' purchase intentions and behavior? Journal of Consumer Marketing, 17(5), 441-453.

Mau, G., Steffen, C., Schramm-Klein, H., \& Steinmann, S. (2012). The Impact of Health Warnings on Children's Consumption Decisions. In M. Eisend, T. Langner, \& S. Okazaki (eds.), Advances in Advertising Research (Vol. III) (pp. 93-103). Wiesbaden: Gabler.

Meulemans, T., Van der Linden, M., \& Perruchet, P. (1998). Implicit sequence learning in children. Journal of Experimental Child Psychology, 69(3), 199-221.

Mischel, W., \& Ebbesen, E. B. (1970). Attention in delay of gratification. Journal of Personality and Social Psychology, 16(2), 329-337.

Mischel, W., Ebbesen, E. B., \& Raskoff Zeiss, A. (1972). Cognitive and attentional mechanisms in delay of gratification. Journal of Personality and Social Psychology, 21(2), 204-218.

Mischel, H. N., \& Mischel, W. (1983). The development of children's knowledge of selfcontrol strategies. Child Development, 54(3), 603-619.

Mitchell, J. (1998). New audiovisual and information services and the protection of children: The European dimension. Journal of Consumer Policy, 21(1), 3-44.

Moffitt, T. E., Arseneault, L., Belsky, D., Dickson, N., Hancox, R. J., Harrington, H., ... Ross, S. (2011). A gradient of childhood self-control predicts health, wealth, and public safety. Proceedings of the National Academy of Sciences, 108(7), 2693-2698.

Moses, L. J., \& Baldwin, D. A. (2005). What can the study of cognitive development reveal about children's ability to appreciate and cope with advertising? Journal of Public Policy \& Marketing, 24(2), 186-201.

Munakata, Y., Snyder, H. R., \& Chatham, C. H. (2012). Developing cognitive control: Three key transitions. Current Directions in Psychological Science, 21(2), 71-77.

Muraven, M., \& Baumeister, R. F. (2000). Self-regulation and depletion of limited resources: Does self-control resemble a muscle? Psychological Bulletin, 126(2), 247-259.

Nagy, Z., Westerberg, H., \& Klingberg, T. (2004). Maturation of white matter is associated 
with the development of cognitive functions during childhood. Journal of Cognitive Neuroscience, 16(7), 1227-1233.

Nairn, A., \& Fine, C. (2008). Who's messing with my mind? International Journal of Advertising, 27(3), 447-470.

Olson, M. A., \& Fazio, R. H. (2001). Implicit attitude formation through classical conditioning. Psychological Science, 12(5), 413-417.

Piachaud, D. (2008). Freedom to be a child: Commercial pressures on children. Social Policy and Society, 7(04).

Piquero, A. R., Jennings, W. G., \& Farrington, D. P. (2010). On the malleability of selfcontrol: Theoretical and policy implications regarding a general theory of crime. Justice Quarterly, 27(6), 803-834.

Posner, M. I., \& Rothbart, M. K. (2000). Developing mechanisms of self-regulation. Development and Psychopathology, 12(03), 427-441.

Pratkanis, A. R., Greenwald, A. G., Leippe, M. R., \& Baumgardner, M. H. (1988). In search of reliable persuasion effects: III. The sleeper effect is dead: Long live the sleeper effect. Journal of Personality and Social Psychology, 54(2), 203-218.

Reber, A. S. (1989). Implicit learning and tacit knowledge. Journal of Experimental Psychology: General, 118(3), 219-235.

Reber, P. J. (2013). The neural basis of implicit learning and memory: A review of neuropsychological and neuroimaging research. Neuropsychologia, 51(10), 2026-2042.

Roberts, D. F. (1983). Children and commercials. Prevention in Human Services, 2(1-2), 1935.

Roberts, D. F., Christenson, P., Gibson, W. A., Mooser, L., \& Goldberg, M. E. (1980). Developing discriminating consumers. Journal of Communication, 30(3), 94-105.

Rozendaal, E., Buijzen, M., \& Valkenburg, P. (2010). Comparing children's and adults' cognitive advertising competences in the Netherlands. Journal of Children and Media, 4(1), 77-89.

Rozendaal, E., Lapierre, M. A., van Reijmersdal, E. A., \& Buijzen, M. (2011). Reconsidering advertising literacy as a defense against advertising effects. Media Psychology, 14(4), 333-354.

Saffran, J. R., Newport, E. L., Aslin, R. N., Tunick, R. A., \& Barrueco, S. (1997). Incidental language learning: Listening (and learning) out of the corner of your ear. Psychological Science, 8(2), 101-105.

Scarabis, M., Florack, A., \& Gosejohann, S. (2006). When consumers follow their feelings: 
The impact of affective or cognitive focus on the basis of consumers' choice. Psychology and Marketing, 23(12), 1015-1034.

Shah, J. Y. (2003). Automatic for the people: How representations of significant others implicitly affect goal pursuit. Journal of Personality and Social Psychology, 84(4), 661681.

Shah, J. Y., Friedman, R., \& Kruglanski, A. W. (2002). Forgetting all else: On the antecedents and consequences of goal shielding. Journal of Personality and Social Psychology, 83(6), 1261-1280.

Shiffrin, R. M., \& Schneider, W. (1977). Controlled and automatic human information processing: II. Perceptual learning, automatic attending and a general theory. Psychological Review, 84(2), 127-190.

Shimp, T. A., Stuart, E. W., \& Engle, R. W. (1991). A program of classical conditioning experiments testing variations in the conditioned stimulus and context. Journal of Consumer Research, 18(1), 1-12.

Shoda, Y., Mischel, W., \& Peake, P. K. (1990). Predicting adolescent cognitive and selfregulatory competencies from preschool delay of gratification: Identifying diagnostic conditions. Developmental Psychology, 26(6), 978-986.

Sowell, E. R., Thompson, P. M., Holmes, C. J., Jernigan, T. L., \& Toga, A. W. (1999). In vivo evidence for post-adolescent brain maturation in frontal and striatal regions. Nature Neuroscience, 2(10), 859-861.

Sowell, E. R., Thompson, P. M., Leonard, C. M., Welcome, S. E., Kan, E., \& Toga, A. W. (2004). Longitudinal mapping of cortical thickness and brain growth in normal children. The Journal of Neuroscience, 24(38), 8223-8231.

Strack, F., \& Deutsch, R. (2004). Reflective and impulsive determinants of social behavior. Personality and Social Psychology Review, 8(3), 220-247.

Strack, F., Werth, L., \& Deutsch, R. (2006). Reflective and impulsive determinants of consumer behavior. Journal of Consumer Psychology, 16(3), 205-216.

Sullivan, R. M., Taborsky-Barba, S., Mendoza, R., Itano, A., Leon, M., Cotman, C. W., Payne, T. F., \& Lott, I. (1991). Olfactory classical conditioning in neonates. Pediatrics, $87(4), 511-518$.

The Henry J. Kaiser Family Foundation Trust (2004). The role of media in childhood obesity. Retrieved July 19, 20123 from $\mathrm{http}: / /$ kaiserfamilyfoundation.files.wordpress.com/2013/01/the-role-of-media-inchildhood-obesity.pdf 
Thomson Media Control. (2009). Werbeausgaben der Wirtschaftsbranche Baby und Kinder. Retrieved from http://de.statista.com/statistik/daten/studie/1729/umfrage/werbeausgaben-derwirtschaftsbranche-baby-und-kinder-im-jahr-2008/

Turley, L. W., \& Milliman, R. E. (2000). Atmospheric effects on shopping behavior: A review of the experimental evidence. Journal of Business Research, 49(2), 193-211.

Vazsonyi, A. T., \& Huang, L. (2010). Where self-control comes from: On the development of self-control and its relationship to deviance over time. Developmental Psychology, $46(1), 245-257$.

Vinter, A., \& Perruchet, P. (2000). Implicit learning in children is not related to age: Evidence from drawing behavior. Child Development, 71(5), 1223-1240.

Vinter, A., \& Perruchet, P. (2002). Implicit motor learning through observational training in adults and children. Memory \& Cognition, 30(2), 256-261.

Webb, T. L., \& Sheeran, P. (2003). Can implementation intentions help to overcome egodepletion? Journal of Experimental Social Psychology, 39(3), 279-286.

Webb, T. L., \& Sheeran, P. (2007). How do implementation intentions promote goal attainment? A test of component processes. Journal of Experimental Social Psychology, 43(2), 295-302.

Welsh, M. C., \& Pennington, B. F. (1988). Assessing frontal lobe functioning in children: Views from developmental psychology. Developmental Neuropsychology, 4(3), 199230.

Welsh, M. C., Pennington, B. F., \& Groisser, D. B. (1991). A normative-developmental study of executive function: A window on prefrontal function in children. Developmental Neuropsychology, 7(2), 131-149.

Wieber, F., von Suchodoletz, A., Heikamp, T., Trommsdorff, G., \& Gollwitzer, P. M. (2011). If-then planning helps school-aged children to ignore attractive distractions. Social Psychology, 42(1), 39-47.

Wills, T. A., Gibbons, F. X., Sargent, J. D., Gerrard, M., Lee, H. R., \& Dal Cin, S. (2010). Good self-control moderates the effect of mass media on adolescent tobacco and alcohol use: tests with studies of children and adolescents. Health Psychology, 29, 539549 .

Wright, P., Friestad, M., \& Boush, D. M. (2005). The development of marketplace persuasion knowledge in children, adolescents, and young adults. Journal of Public Policy \& Marketing, 24(2), 222-233. 
Yang, M., Roskos-Ewoldsen, D., Dinu, L., \& Arpan, L. (2006). The effectiveness of "ingame" advertising: Comparing college students' explicit and implicit memory for brand names. Journal of Advertising, 35(4), 143-152.

Young, B. (2010). Children and advertising. In D. Marshall (Ed.), Understanding childran as consumers (pp. 115-131). London: Sage Publications.

Zajonc, R. B. (1968). Attitudinal effects of mere exposure. Journal of Personality and Social Psychology, 9(2, Pt.2), 1-27. 


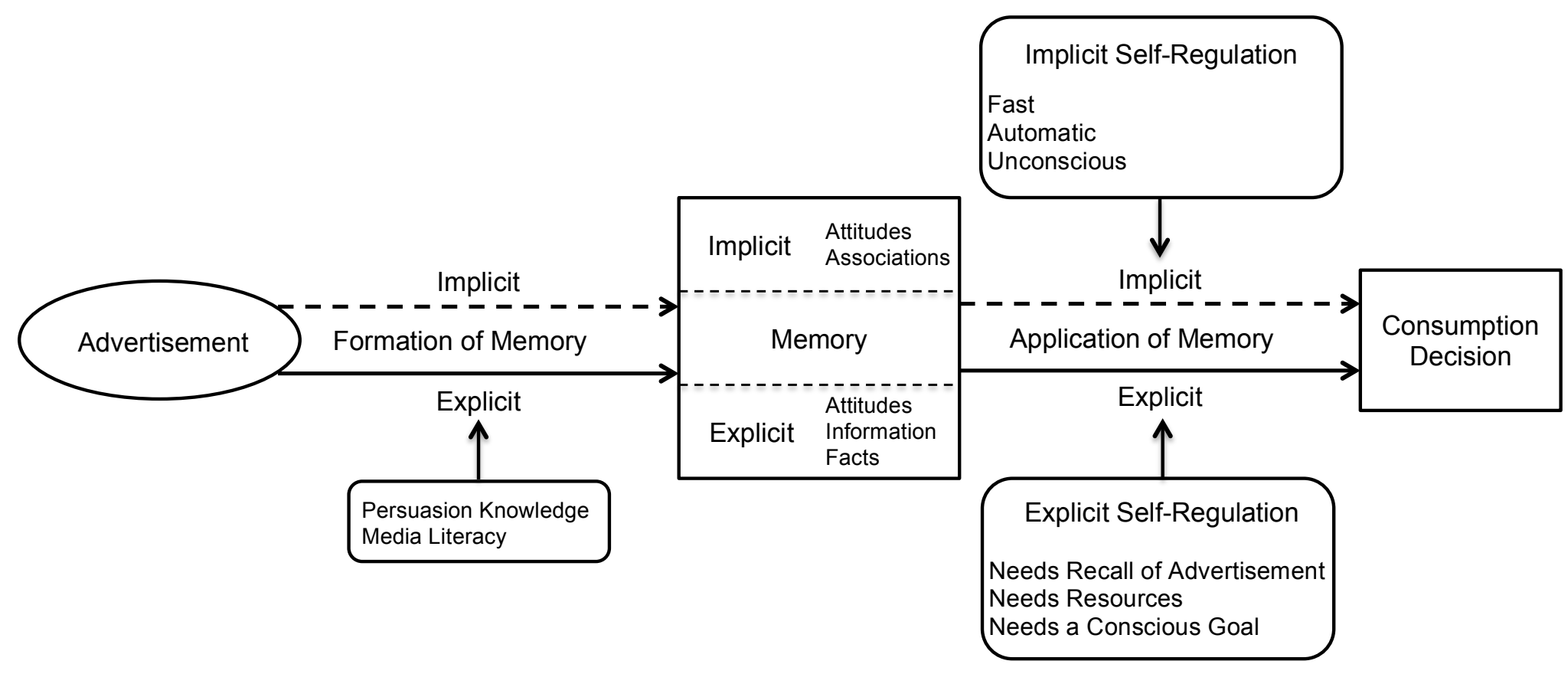

Figure 1. Dual-step and dual-process model of advertising effects. 


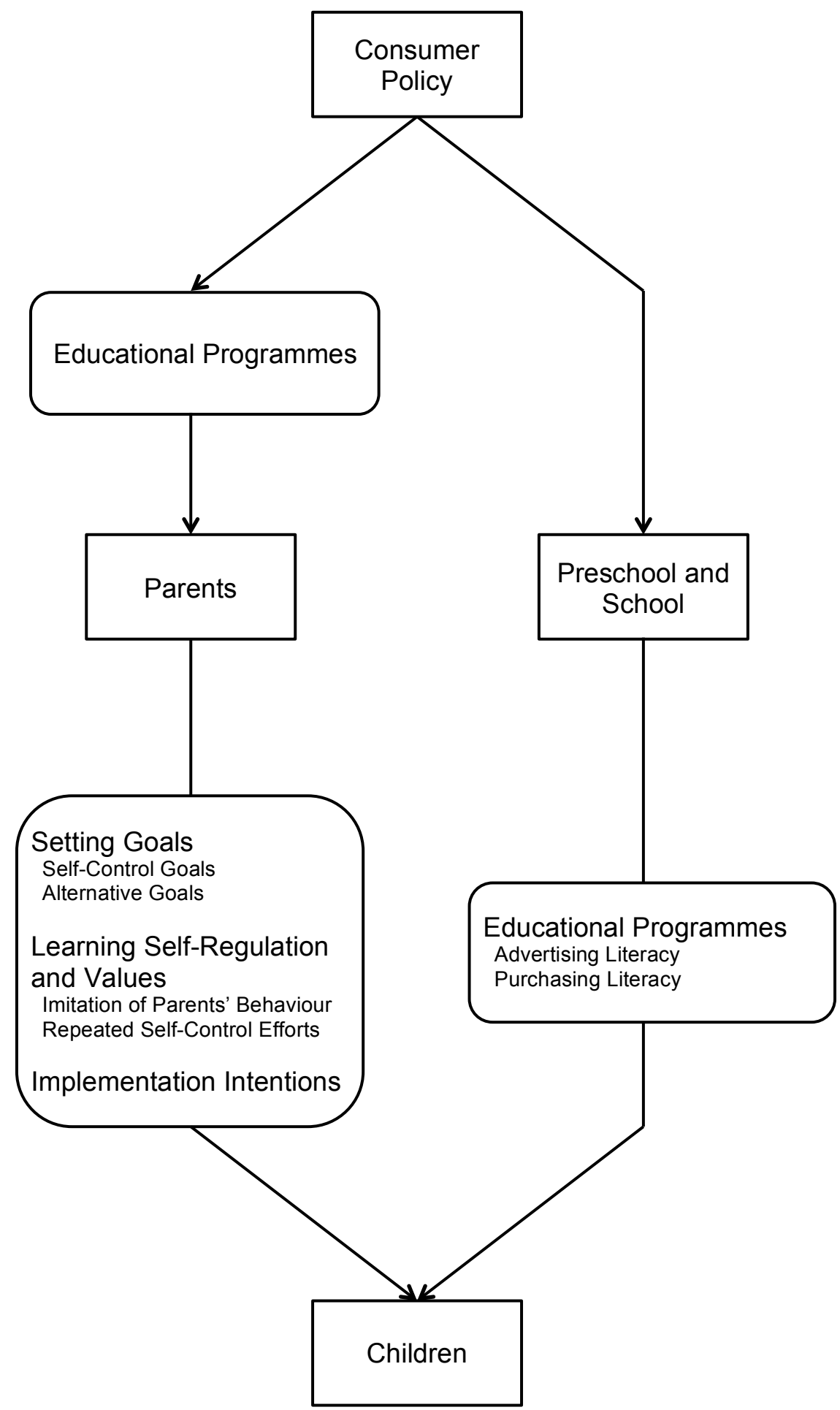

Figure 2. Interventions for reducing the negative effects of advertising on children. 